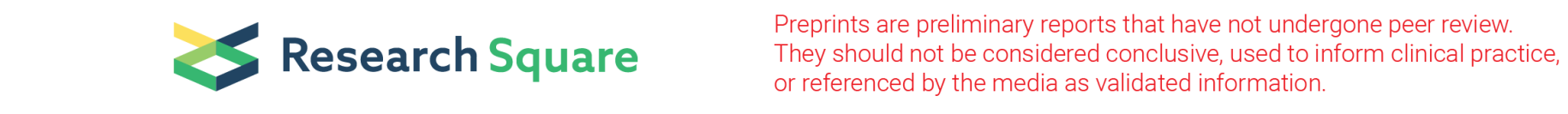

\title{
Dynamic curve analysis of indicators related to lumbar cistern drainage for postoperative meningitis
}

\section{Weining Ma ( $\square$ maweining1985@163.com)}

Shengjing Hospital of China Medical University

\section{Chun Li}

Shengjing Hospital of China Medical University

Lin Cong ( $\nabla$ conglin_medicine@163.com)

Shengjing Hospital of China Medical University

\section{Research}

Keywords: Lumbar cisterna drainage, White blood cell, Polykaryocyte, Drainage volume

Posted Date: April 2nd, 2020

DOI: https://doi.org/10.21203/rs.3.rs-19464/v1

License: (c) (i) This work is licensed under a Creative Commons Attribution 4.0 International License. Read Full License

Version of Record: A version of this preprint was published at World Neurosurgery on July 1st, 2021. See the published version at https://doi.org/10.1016/j.wneu.2021.04.031. 


\section{Abstract}

Background Lumbar cisterna drainage (LCD) is widely used in neurosurgery as an effective treatment for postoperative meningitis, vasospasm of subarachnoid hemorrhage and ventricular system hemorrhage, and for reducing intracranial pressure in patients with severe craniocerebral trauma. The purpose of this work was two-fold: to analyze the dynamic curve of cerebrospinal fluid (CSF) related indices in cases of postoperative meningitis after selective craniotomy and to provide reference data for the clinical treatment with LCD. Methods We conducted a retrospective study of LCD placement in patients who underwent either supratentorial craniotomy $(n=23)$ or subtentorial craniotomy $(m=28)$. Primary outcomes measured included pre-intervention and post-intervention dynamic changes of body temperature, and CSF biochemical parameters (white blood cell (WBC) count, polykaryocyte percentage, protein, glucose and chloride) over the course of 13 days of catheter placement. We also assessed the bivariate correlation between WBC count changes, polykaryocyte percentage, body temperature and daily CSF drainage volume. Finally, we analyzed the effect of average daily drainage volume, antibiotic choice, and surgical site on the WBC count change curves. Results After LCD, a trend of increased WBC count was observed on the first day of drainage, followed by an overall decrease in WBC count. There was a statistically significant $(P<0.05)$ difference between the WBC count before drainage and the WBC count on the fourth day of drainage. Polykaryocyte percentage decreased initially and then increased progressively each day after drainage. There was a negative correlation between the change curve of the WBC count and the curve of daily drainage volume $(r=-0.56)$. When the daily drainage volume was $250-300 \mathrm{ml} / \mathrm{d}$, the change curve pattern of the WBC count was consistent with the overall trend of the WBC count, and there was no significant difference in the curve of the WBC count between different surgical sites $(P>0.05)$. Conclusions LCD is an effective method for the treatment of postoperative meningitis. The WBC count can decrease significantly by the fourth day after drainage, and placement of the LCD for six to seven days is ideal. An average drainage volume of $250-300 \mathrm{ml} / \mathrm{d}$ is safe and effective.

\section{Background}

Lumbar cistern drainage (LCD) is widely used in neurosurgery as an effective way to treat postoperative meningitis [1], vasospasm of subarachnoid hemorrhage [2,3], ventricular system hemorrhage [4] and reduction of intracranial pressure in patients with severe craniocerebral trauma [5]. Of note, meningitis after neurosurgical craniotomy is a common complication that affects the prognosis and length of stay of patients [6]. Although LCD can be used in a variety of clinical cases, there are risks and potential complications, such as infection, given that the process is invasive and requires placement of a drainage tube for a certain period. The white blood cell (WBC) count in cerebrospinal fluid (CSF) and the daily drainage volume of CSF should be observed clinically in order to guide decisions in catheter removal. However, with respect to LCD placement, there is a dearth of information available on how drainage time relates to the change trend of CSF-related indicators, and how these indicators correlate with one another during the interventional treatment process. Therefore, this study retrospectively analyzed 51 cases of LCD due to postoperative meningitis and plotted the dynamic change curves of body temperature, WBC count, polykaryocyte percentage, protein, glucose and chloride over a period of 13 days. The bivariate correlation between WBC count, polykaryocyte percentage, body temperature and daily CSF drainage volume was assessed. Lastly, to provide reference data for the application of LCD in clinical practice, the effect of daily drainage volumes, antibiotic choice and surgical sites on the WBC count change curve was investigated.

\section{Materials And Methods}

\section{Cases and inclusion criteria}

The inclusion criteria of cases in this study were: 1) elective craniotomy; 2) elevated postoperative body temperature which remained above $37.5^{\circ} \mathrm{C}$, with at least one of the following clinical symptoms: headache, neck stiffness, cranial 
nerve irritation symptoms, or disturbance of consciousness; 3) LCD was performed, and 4) in CSF during drainage, WBC count was greater than $500 \times 10^{6} / \mathrm{L}$. In all, 51 patients in Shengjing Hospital of China Medical University met the above criteria between January 2012 and December 2019. Patient demographics included 23 males, 28 females, 23 cases of supratentorial surgery and 28 cases of subtentorial surgery (Table 1). This study was approved by the ethics committee of the Shengjing Hospital of China Medical University. Informed consent was obtained from all patients.

\section{Research process}

For all 51 cases, body temperature and routine CSF biochemical indicators, including WBC count, polykaryocyte percentage, protein, glucose and chloride, were recorded daily prior to catheter placement and for a period of 13 days after catheter placement. A bivariate correlation analysis was performed on the daily CSF drainage change curve, body temperature change curve, WBC change curve and polykaryocyte percentage change curve. Finally, according to the average daily drainage volume of each case, the differences in WBC change curves and drainage time between different drainage volumes were analyzed. According to the types of antibiotics used in the drainage process, the WBC change curve, drainage time and differences in the daily drainage volume between different antibiotics were analyzed. The differences in drainage time, daily drainage volume, body temperature curve, white blood cell change curve and polykaryocyte percentage change curve for various surgical sites were also analyzed (Figure 1).

\section{Statistical analysis}

Data were analyzed using SPSS17.0 software for statistical calculation. A $t$-test was used to determine the statistical differences between body temperature, WBC count, polykaryocyte percentage, protein, glucose and chloride at different time points. The same method was adopted to calculate statistical differences in drainage time and daily drainage volume between different groups. Lastly, the bivariate correlation between daily CSF drainage volume, body temperature, WBC and polykaryocyte percentage were analyzed. $P<0.05$ was considered statistically significant.

\section{Results}

\section{General change trend of routine CSF biochemical tests}

The change trend of body temperature after LCD was as follows: body temperature first decreased, increased and then decreased. Body temperature on the second day after drainage was significantly different from body temperature before drainage $(P<0.001)$. Body temperature began to increase on the sixth day after drainage and reached the highest point on the ninth day after drainage, after which it began to decrease (Figure $2 A$ ). The WBC count on the first day after drainage was significantly higher than WBC count before drainage $(P<0.001)$, and then began to show an overall downward trend. By day 4, the WBC count was significantly lower than the WBC count before drainage $(P=0.004<0.01)$ (Figure 2B). The change trend of the polykaryocyte percentage was similar to that of body temperature; it began to decrease significantly on the third day after drainage $(P=0.004<0.01)$ (Figure $2 C)$. The time node was synchronized with the change of WBC. Of note, protein was above the normal range during drainage (Figure 2D), the change of glucose was within the normal range during drainage (Figure $2 E$ ) and the change of chloride was essentially below the normal range during drainage (Figure 2F). These trends were overall consistent with the characteristics of meningitis.

\section{Correlation analysis of daily CSF drainage with body temperature and WBC}

Correlation analysis demonstrated a negative correlation between daily CSF drainage and body temperature $(r=-0.14)$, and there was no statistical difference between the two trends $(P=0.65>0.05)$ (Figure $3 A, 3 B$ ). There was also a negative correlation between daily CSF drainage and WBC count $(r=-0.56)$, with a statistical difference between the two trends $(P=0.046<0.05)$ (Figure 3C, 3D). There was a negative correlation between daily CSF flow and polykaryocyte percentage 
$(r=-0.29)$, with no statistical difference between the two trends $(P=0.34>0.05)$ (Figure $3 E, 3 F)$. Lastly, there was a positive correlation between WBC count and polykaryocyte percentage $(r=0.696)$, and the change trend of the two was statistically different $(P=0.006<0.01)$ (Figure $3 G, 3 H)$.

When the daily CSF drainage volume was 250-300 ml, the WBC change curve was most consistent with the overall WBC change curve

Based on the observed average daily CSF drainage volumes, the patients were divided into five groups: $100-150 \mathrm{ml} / \mathrm{d}$ $(n=11,21.6 \%), 150-200 \mathrm{ml} / \mathrm{d}(\mathrm{n}=19,37.3 \%), 200-250 \mathrm{ml} / \mathrm{d}(\mathrm{n}=9,17.6 \%), 250-300 \mathrm{ml} / \mathrm{d}(\mathrm{n}=8,15.7 \%)$ and greater than 300 $\mathrm{ml} / \mathrm{d}(\mathrm{n}=4,7.8 \%)$. The WBC change curves of the five groups all increased on the first day after drainage, and then presented an overall trend of decline. Among them, the WBC of the $250-300 \mathrm{ml} / \mathrm{d}$ group decreased the most significantly on the fourth day after drainage $(P=0.006<0.01)$, and the subsequent fluctuation was smaller, which was most consistent with the overall WBC curve when compared with the other subgroups (Figure $4 A$ ). In addition, there was no significant difference in drainage time between the five groups (Figure 4B), indicating that although the WBC trend for the 200-250 $\mathrm{ml} / \mathrm{d}$ group was most consistent with the overall WBC change curve, more daily flow did not shorten duration of LCD placement.

\section{The type of antibiotic affects the WBC change curve}

Patients were divided into four groups according to the types of antibiotics used during drainage, as follows: cephalosporin treatment group (more than 3 generations of cephalosporin) ( $n=16,31.4 \%)$, meropenem treatment group $(n=10,19.6 \%)$, linezolid treatment group $(n=7,13.7 \%)$ and multiple antibiotic treatment group $(n=18,35.3 \%)$. The WBC count change curve of the meropenem group and the multiple antibiotic group was consistent with the overall curve, while the cephalosporin group and linezolid group showed some fluctuations. The decrease of WBC on the fourth day of drainage was the most significant in the meropenem treatment group $(P=0.011<0.05)$ (Figure $4 C)$. In addition, the drainage time between the meropenem treatment group and the cephalosporin treatment group was relatively short, and there was a statistical difference in the drainage time between the cephalosporin treatment group and the linezolid treatment group $(P=0.012<0.05)$ and the multiple antibiotic treatment group $(P=0.021<0.05)$ (Figure $4 D)$. There was no significant statistical difference in the daily drainage volumes of the four groups $(P>0.05)$ (Figure $4 E)$.

\section{Differences in body temperature and WBC curve in different surgical sites}

Based on the surgical site, patients were divided into two groups: the supratentorial craniotomy group $(n=23,45.1 \%)$ and the subtentorial craniotomy group $(n=28,54.9 \%)$. A statistical difference was observed in the drainage time between the two groups $(P=0.012<0.05)$, with a longer drainage time in the supratentorial craniotomy group, and no significant statistical difference was observed in the daily drainage volume between the two groups $(P>0.05)($ Figure 5A). The trends of body temperature, WBC and polykaryocyte percentage were similar in the two groups. However, according to the trend of body temperature changes of the two groups, the overall body temperature of the supratentorial surgery group was higher than that of the subtentorial surgery group. When comparing body temperature at each time point before and 5 days after drainage, there were statistically significant differences in body temperature between the two groups (Figure $5 B$ ), suggesting that symptoms of postoperative meningitis may vary in different surgical sites and that symptoms of hyperthermia are more common in the supratentorial surgery group. Overall, the differences in WBC count (Figure 5C) and polykaryocyte percentage (Figure $5 D$ ) at each time point between the two groups were not particularly significant.

\section{Discussion}

$L C D$ retention time of 6 to 7 days may be ideal 
In this retrospective study of 51 patients undergoing LCD placement, we found an average drainage duration of 7 days, with the overall body temperature curve showing a trend of decrease, increase and then decrease, in which body temperature dropped to the nadir on the sixth day after drainage and reached an average of $37.3^{\circ} \mathrm{C}$. In addition, the WBC count curve changed significantly from day four after drainage, when the average leucocyte count was $840 \times 10^{6} / \mathrm{L}$, after which it decreased to $440 \times 10^{6} / \mathrm{L}$ on day six, considered the minimum WBC count required for enrollment. Similarly, the polykaryocyte percentage dropped to the nadir of $42.1 \%$, followed by an upward trend for body temperature, WBC count and polykaryocyte percentage.

LCD is an effective treatment for postoperative meningitis. However, prolonged indwelling of drainage tubes in vivo may increase the risk of drainage tube-related infections. One study [7] demonstrated that the infection rate associated with LCD is $31.28 \%$ between three and seven days of drainage, but when LCD exceeds seven days, the infection rate rises to 63.33\%. In addition, another study [8] showed that between four and nine days is the peak period of infection associated with LCD. The WBC count change curve seen in our study showed a small increase after day seven and a more significant increase in the polykaryocyte percentage. It is suggested that the duration of drainage at any time is prolonged and the risk of infection associated with drainage tubes is increasing. Therefore, the rational management of CSF drainage tube affects the development of postoperative meningitis [9].

\section{Exploration of daily CSF drainage volume}

The daily CSF volume during LCD is a clinical index that needs to be measured and observed closely. The first study using an external lumbar drainage system was reported by Voursh in 1963 [10]. Although the technique of LCD is relatively safe and effective, it also has certain risks and fatal complications, such as headache with low cranial pressure and even cerebral hernia $[11,12]$. The occurrence of cerebral hernia is related to the rate of drainage. The rate of CSF production in normal adults is $20 \mathrm{ml} / \mathrm{h}$, indicating that about $480 \mathrm{ml}$ CSF is produced every day.

Setting the drainage volume in the lumbar cisterna drainage process is very important. However, as far as we know, there are no recommendations on the average daily CSF drainage volume. In our study, the average total drainage volume was $1428 \mathrm{ml}$, the average daily drainage volume was $207 \mathrm{ml}$ and the average CSF replacement was about three times. Of the 51 patients, two patients presented with headache symptoms of low cranial pressure during LCD, and the average daily drainage volume of the two patients was $380 \mathrm{ml}$ and $404 \mathrm{ml}$, respectively. The risk of low cranial pressure was higher (50\%) when the average drainage volume was above $300 \mathrm{ml} / \mathrm{d}$. In addition, there was a negative correlation between the daily drainage volume and the WBC count. The average daily drainage volume on the first day was $149 \mathrm{ml}$, after which it increased to $221 \mathrm{ml} / \mathrm{d}$ and remained above the baseline of $200 \mathrm{ml} / \mathrm{d}$ thereafter. With the accumulation of drainage volume, the WBC count showed a decreasing trend. Of the four groups of daily drainage, the most significant change in the WBC was noted when the daily drainage volume of CSF was between 250 and $300 \mathrm{ml}$ since the average WBC count was $2619 \times 10^{6} / \mathrm{L}$ before drainage and subsequently decreased to $655 \times 10^{6} / \mathrm{L}$ on day four of drainage. When the daily CSF drainage was maintained between 200 and $300 \mathrm{ml}$, patients did not show symptoms of headache with low cranial pressure. This was consistent with the control of CSF drainage of $10 \mathrm{ml} / \mathrm{h}$ by Nanidis $\mathrm{N}$ et al. [13]. Therefore, in order to achieve the goal of reducing the WBC count of CSF more quickly, it is relatively safe and effective to maintain the average daily drainage volume at $250-300 \mathrm{ml}$.

\section{Selection of antibiotics during $L C D$}

Postoperative meningitis after craniotomy is a common complication of neurosurgery and affects the prognosis of surgical patients. Some malignant tumors and tumors of the ventricular system are prone to cause postoperative intracranial infection [14,15]. Bacterial meningitis is more common in infection [16]. In our study, 51 patients were treated with at least one antibiotic during drainage. Among them, the WBC count change curve of the meropenem treatment group showed the most significant decrease in the WBC count at day four of drainage, and the drainage time of the LCD 
was shorter in the cephalosporin treatment group and the meropenem treatment group, suggesting that the infection rate of gram-negative bacilli may be higher in our cases. However, in all 51 cases, multiple CSF bacterial cultures were negative and the pathogen of infection could not be identified, which is also a limitation of this study. In our experience, the use of antibiotics during LCD can, on the one hand, treat meningitis and, on the other hand, reduce the risk of catheter-related infections.

In addition, we found that there were notable differences in the clinical manifestations of postoperative meningitis among patients with different surgical sites. Patients who underwent supratentorial surgery tended to have a higher degree of fever, while patients who underwent subtentorial surgery had more symptoms of meningeal irritation, which required clinical screening.

\section{Conclusion}

The study investigated parameters surrounding CSF change parameters when using LCD as an effective method to treat postoperative meningitis. We included 51 patients in this retrospective study and assessed the correlation and statistical significance of multiple parameters over a study duration of 13 days. The WBC count on day four after drainage showed a significant decrease compared with the WBC count before drainage. These results indicate that LCD retention time of six to seven days is ideal based on body temperature, WBC count and polykaryocyte percentage, and prolonged retention time may increase the risk associated with the drainage tube. Patients were treated with at least one antibiotic during the LCD process, and results suggest a possible prevalence of gram-negative bacilli given trends from antibiotic correlation studies.

\section{Declarations}

\section{Consent for publication}

All authors consent to the publication of this manuscript.

\section{Funding}

This research did not receive any specific grant from funding agencies in the public, commercial, or not-for-profit sectors.

\section{Acknowledgements}

Not applicable.

\section{Competing interests}

The authors declare that they have no competing interests.

\section{Author contributions}

All authors were involved in the study design, interpretation of the results, and the reviewing and approval of the manuscript, and in the decision to submit the article for publication. All authors also confirm accountability for the accuracy and integrity of the work.

\section{Ethics approval and consent to participate}

Informed consent from each patient was carried out before the research. The use of the research protocol was approved by the Ethics and the Human Research Review Committee of Shengjing Hospital of China Medical University. 
Availability of data and materials

To get the raw data, please send an email to authors. (conglin_medicine@163.com)

\section{References}

1. Ren Y, Liu X, You C, Zhang Y, Du L, Hui X, Liu W, Ma L, Liu J. Efficacy of Closed Continuous Lumbar Drainage on the Treatment of Postcraniotomy Meningitis: A Retrospective Analysis of 1062 Cases. World Neurosurg.2017; 106: 925-931.

2. Otawara Y, Ogasawara K, Kubo Y, Sasoh M, Ogawa A. Effect of continuous cisternal cerebrospinal fluid drainage for patients with thin subarachnoid hemorrhage. Vasc Health Risk Manag.2007; 3(4): 401-404.

3. Qian C, Yu X, Chen J, Gu C, Wang L, Chen G, Dai Y. Effect of the drainage of cerebrospinal fluid in patients with aneurismal subarachnoid hemorrhage: A meta-analysis. Medicine (Baltimore).2016; 95(41): e5140.

4. Xia D, Jiang X, Li Z, Jin Y, Dai Y. External ventricular drainage combined with continuous lumbar drainage in the treatment of ventricular hemorrhage. Ther Clin Risk Manag.2019; 15: 677-682.

5. Bauer M, Sohm F, Thomé C, Ortler M. Refractory intracranial hypertension in traumatic brain injury: Proposal for a novel score to assess the safety of lumbar cerebrospinal fluid drainage. Surg Neurol Int.2017; 8: 265.

6. Hussein K, Bitterman R, Shofty B, Paul M, Neuberger A. Management of postneurosurgical meningitis: narrative review. Clin Microbiol Infect.2017; 23(9): 621-628.

7. Chen C, Zhang B, Yu S, Sun F, Ruan Q, Zhang W, Shao L, Chen S. The incidence and risk factors of meningitis after major craniotomy in China: a retrospectivecohort study. PLoS One.2014; 9(7): e101961.

8. Scheithauer S, Bürgel U, Bickenbach J, Häfner H, Haase G, Waitschies B, Reinges MH, Lemmen SW.

External ventricular and lumbar drainage-associated meningoventriculitis: prospective analysis of time-dependent infection rates and risk factor analysis. Infection.2010; 38(3): 205-209.

9. Soavi L, Rosina M, Stefini R, Fratianni A, Cadeo B, Magri S, Latronico N, Fontanella M, Signorini L. Postneurosurgical meningitis: Management of cerebrospinal fluid drainage catheters influencesthe evolution of infection. Surg Neurol Int.2016; 7(Suppl 39): S927-S934.

10. Wahlig JB, Welch WC, Kang JD, Jungreis CA. Cervical intrathecal catheter placement for cerebrospinal fluid drainage: technical case report. Neurosurgery.1999; 44(2): 419-421.

11. Manley GT, Dillon W.

Acute posterior fossa syndrome following lumbar drainage for treatment of suboccipitalpseudomeningocele. Report of three cases. J Neurosurg.2000; 92(3): 469-474.

12. Açikbaş SC, Akyüz M, Kazan S, Tuncer R. Complications of closed continuous lumbar drainage of cerebrospinal fluid. Acta Neurochir (Wien).2002; 144(5): 475-480.

13. Nanidis N, Korfias S, Sakas DE. Flow-regulated external lumbar drain: applications and complications. Acta Neurochir (Wien).2014; 156(11): 2201-2205.

14. Zhou H, Zhang X. Intracranial malignant lesions correlate with the requirement for a long treatment course in postoperative central nervous system infection. Neuropsychiatr Dis Treat.2014; 10: 20712077.

15. Huang B, Ren Y, Wang C, Lan Z, Hui X, Liu W, Zhang Y. Risk factors for postoperative meningitis after microsurgery for vestibular schwannoma. PLoS One.2019; 14(7): e0217253.

16. Chen S, Cui A, Yu K, Huang C, Zhu M, Chen M. Risk Factors Associated with Meningitis after Neurosurgery: A Retrospective Cohort Study in a Chinese Hospital. World Neurosurg.2018; 111: e546-e563.

Page $7 / 12$ 
Table 1. The demographic of the cases

\begin{tabular}{|c|c|c|c|c|c|c|}
\hline Case number & Sex & $\begin{array}{c}\text { Age } \\
\text { (Years) }\end{array}$ & Surgical site & $\begin{array}{l}\text { Duration for lumbar drainage } \\
\text { (Days) }\end{array}$ & $\begin{array}{l}\text { Total drainage volume } \\
(\mathrm{mL})\end{array}$ & $\begin{array}{l}\text { Average daily drainage volume } \\
(\mathrm{mL})\end{array}$ \\
\hline 1 & Female & 34 & Right frontotemporal lobe & 10 & 1320 & 132 \\
\hline 2 & Male & 48 & Right lateral ventricle & 10 & 2055 & 206 \\
\hline 3 & Female & 70 & Right cerebellopontine angle & 11 & 2640 & 240 \\
\hline 4 & Male & 37 & Left frontal lobe & 13 & 2510 & 193 \\
\hline 5 & Female & 63 & Trigeminal nerve & 6 & 890 & 148 \\
\hline 6 & Male & 29 & Left temporal lobe & 7 & 1060 & 1514 \\
\hline 7 & Male & 43 & Left cerebellopontine angle & 8 & 1090 & 136 \\
\hline 8 & Male & 53 & Cerebellum & 8 & 980 & 122 \\
\hline 9 & Male & 45 & Left temporal lobe & 4 & 630 & 158 \\
\hline 10 & Male & 61 & Trigeminal nerve & 5 & 1380 & 276 \\
\hline 11 & Female & 53 & Facial nerve & 6 & 1130 & 188 \\
\hline 12 & Female & 67 & Facial nerve & 3 & 405 & 135 \\
\hline 13 & Male & 66 & Trigeminal nerve & 5 & 1245 & 249 \\
\hline 14 & Female & 59 & Left cerebellopontine angle & 7 & 832 & 119 \\
\hline 15 & Female & 69 & Right frontal lobe & 7 & 1795 & 256 \\
\hline 16 & Male & 51 & Right cerebellopontine angle & 5 & 1420 & 284 \\
\hline 17 & Male & 38 & Facial nerve & 7 & 1287 & 184 \\
\hline 18 & Male & 29 & Right frontal lobe & 6 & 1450 & 242 \\
\hline 19 & Female & 60 & Left temporal lobe & 3 & 550 & 183 \\
\hline 20 & Female & 61 & Trigeminal nerve & 5 & 875 & 175 \\
\hline 21 & Male & 54 & Facial nerve & 4 & 650 & 163 \\
\hline 22 & Female & 20 & Hypothalamus & 6 & 845 & 141 \\
\hline 23 & Male & 61 & Right cerebellopontine angle & 4 & 730 & 183 \\
\hline 24 & Male & 59 & Brain stem & 7 & 2040 & 291 \\
\hline 25 & Female & 54 & Left cerebellopontine angle & 9 & 1350 & 150 \\
\hline 26 & Male & 43 & Right temporal lobe & 6 & 1530 & 255 \\
\hline 27 & Male & 23 & Right temporal lobe & 7 & 1130 & 161 \\
\hline 28 & Female & 47 & Multiple supratentorial lesions & 11 & 2750 & 250 \\
\hline 29 & Female & 47 & Left cerebellopontine angle & 5 & 910 & 182 \\
\hline 30 & Female & 55 & Facial nerve & 5 & 1600 & 320 \\
\hline 31 & Male & 39 & Left frontal lobe & 7 & 2020 & 289 \\
\hline 32 & Female & 64 & Right middle cranial fossa base & 5 & 1160 & 232 \\
\hline 33 & Female & 41 & Right frontal lobe & 12 & 3565 & 297 \\
\hline 34 & Female & 60 & Left cerebellopontine angle & 7 & 920 & 131 \\
\hline 35 & Female & 51 & Right temporal lobe & 8 & 1190 & 149 \\
\hline 36 & Female & 44 & Right temporal lobe & 9 & 1880 & 209 \\
\hline 37 & Female & 46 & Right temporal lobe & 7 & 1380 & 197 \\
\hline 38 & Female & 18 & Left cerebellopontine angle & 8 & 1590 & 199 \\
\hline 39 & Female & 52 & Trigeminal nerve & 6 & 865 & 144 \\
\hline 40 & Male & 41 & Left frontotemporal lobe & 10 & 2020 & 202 \\
\hline 41 & Male & 27 & Right occipital lobe & 7 & 1560 & 223 \\
\hline 42 & Male & 27 & Saddle area & 9 & 1755 & 195 \\
\hline 43 & Female & 63 & Trigeminal nerve & 4 & 635 & 159 \\
\hline 44 & Female & 65 & Trigeminal nerve & 5 & 920 & 184 \\
\hline 45 & Female & 43 & Right cerebellopontine angle & 8 & 1720 & 215 \\
\hline 46 & Male & 51 & Right temporal lobe & 7 & 872 & 125 \\
\hline 47 & Male & 29 & Left temporal lobe & 8 & 1570 & 196 \\
\hline 48 & Male & 39 & Facial nerve & 7 & 1222 & 175 \\
\hline 49 & Female & 59 & Trigeminal nerve & 6 & 2150 & 358 \\
\hline 50 & Female & 50 & Cerebellum & 9 & 3640 & 404 \\
\hline 51 & Female & 26 & Cerebellum & 3 & 1140 & 380 \\
\hline
\end{tabular}

\section{Figures}




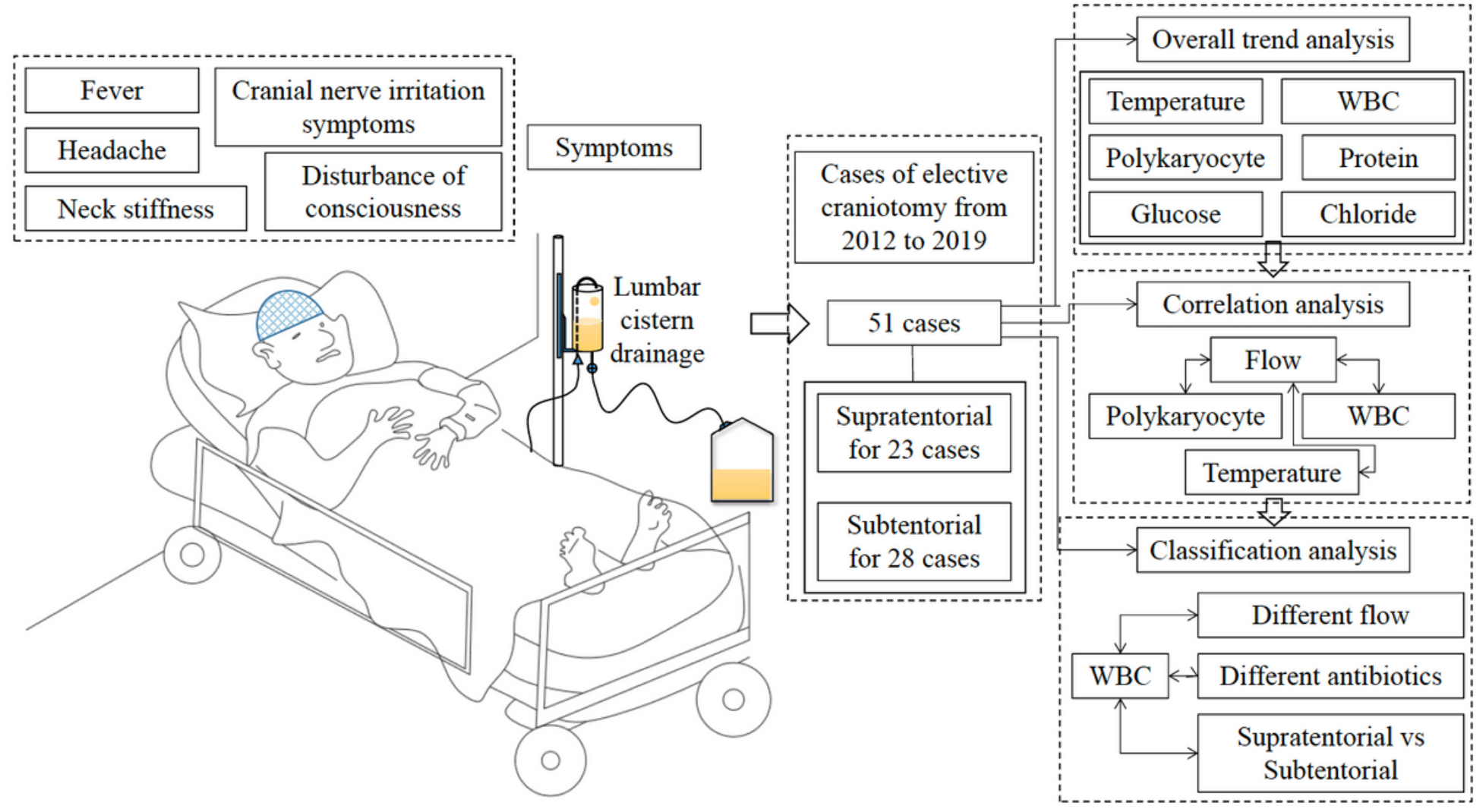

Figure 1

The research framework for this study.
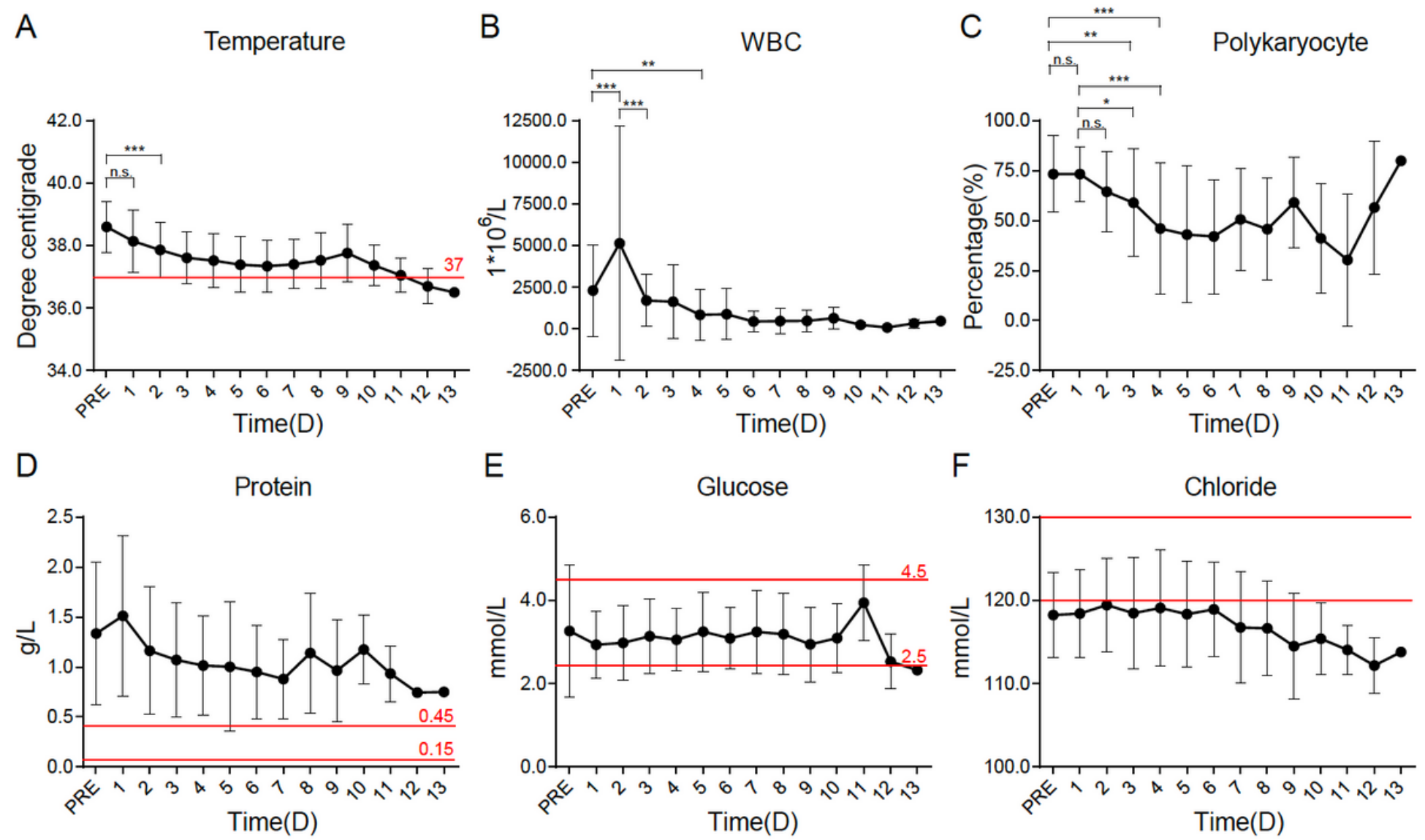

F

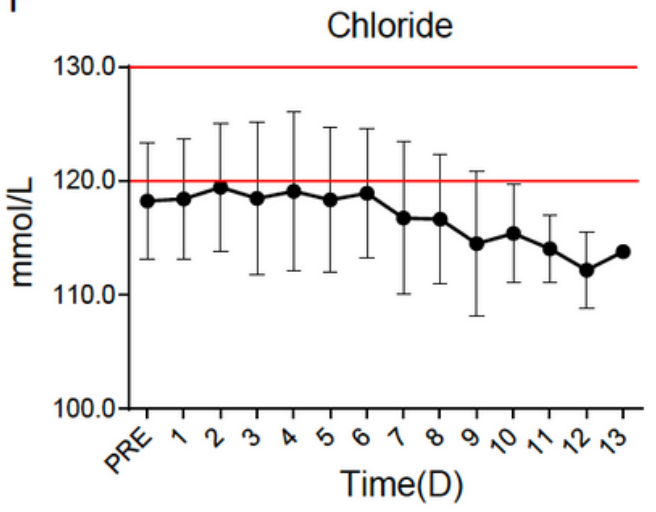


Figure 2

Changes of body temperature and CSF biochemical parameters before and after LCD. A. Body temperature; B. WBC count; C. Polykaryocyte percentage; D. Protein; E. Glucose; F. Chloride. n.s.: no statistical significance; *: $P<0.05$; $* *$ :

$P<0.01 ; * * *: P<0.001$. Data were represented as mean \pm s.e. $m$.
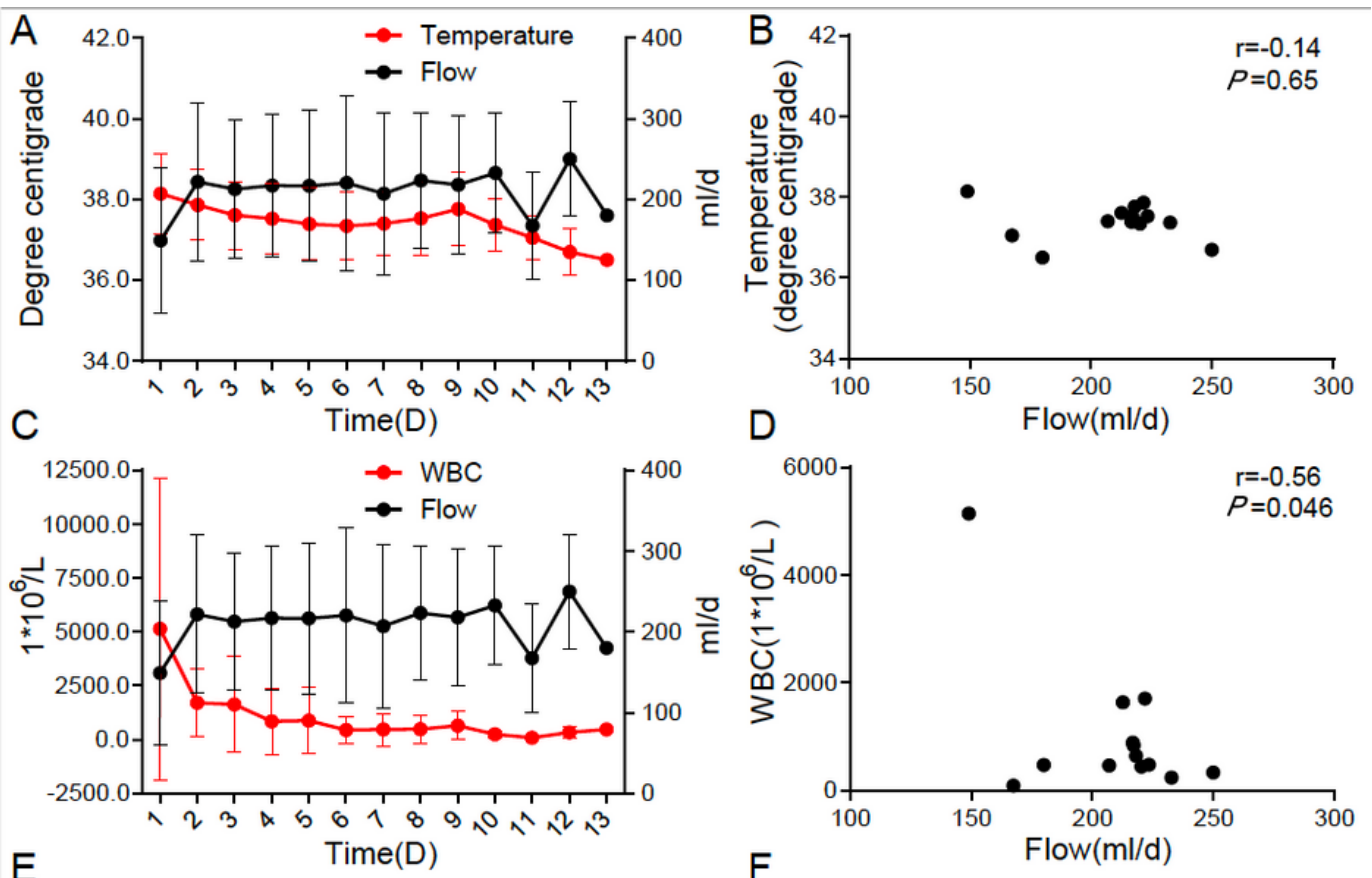

E
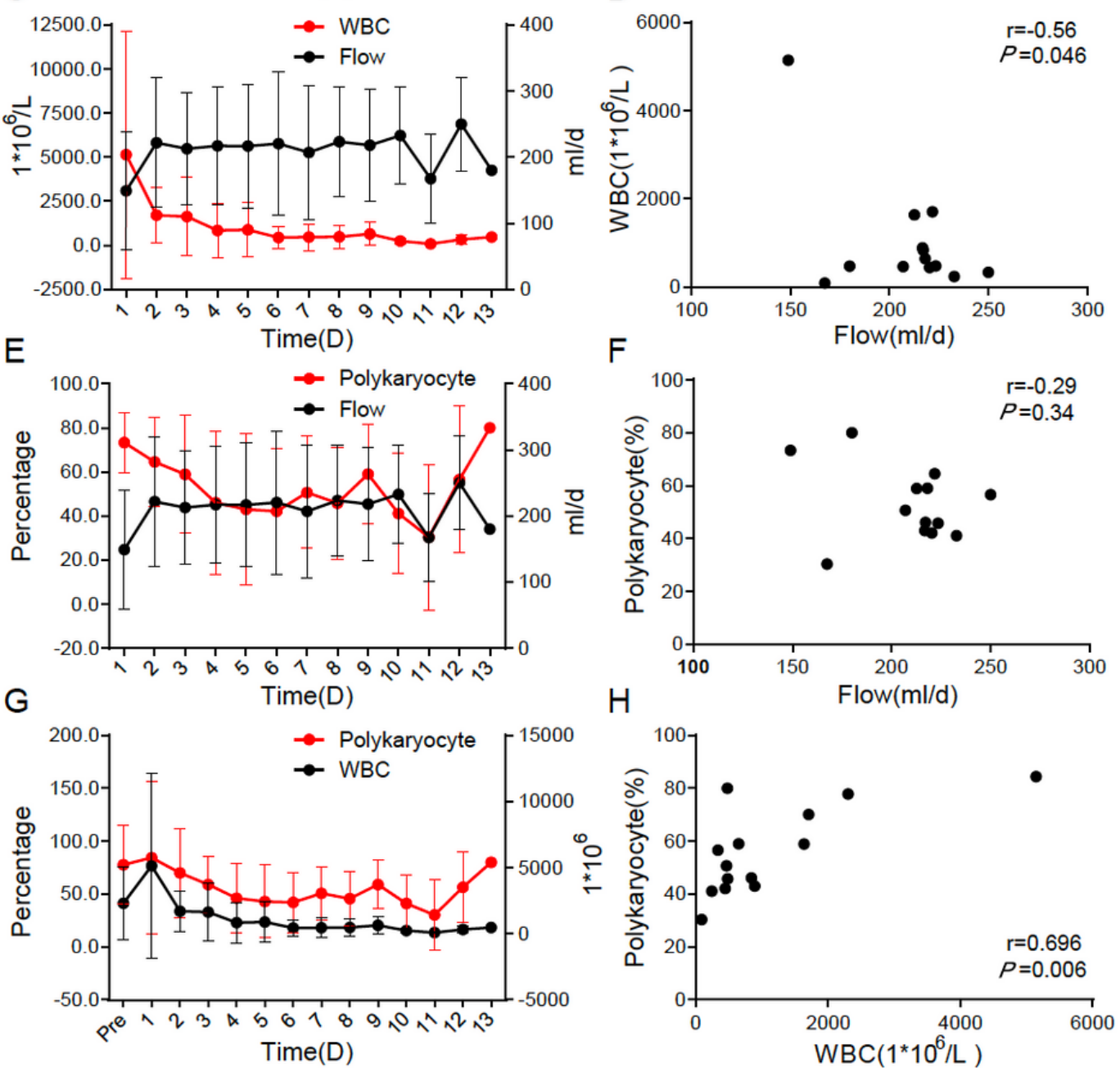

Figure 3

Correlation analysis. A. The change curve of body temperature and the change curve of daily CSF drainage volume; $\mathrm{B}$. Correlation analysis of body temperature and daily CSF drainage volume; C. The change curve of WBC count and the change curve of daily CSF drainage volume; D. Correlation analysis of WBC count and daily CSF drainage volume; $E$. The change curve of polykaryocyte percentage and the change curve of daily CSF drainage volume; F. Correlation analysis of polykaryocyte percentage and daily CSF drainage volume; G. The change curve of WBC count and the change curve of 
polykaryocyte percentage; $\mathrm{H}$. Correlation analysis of WBC count and polykaryocyte percentage. Data were represented as mean \pm s.e.m.
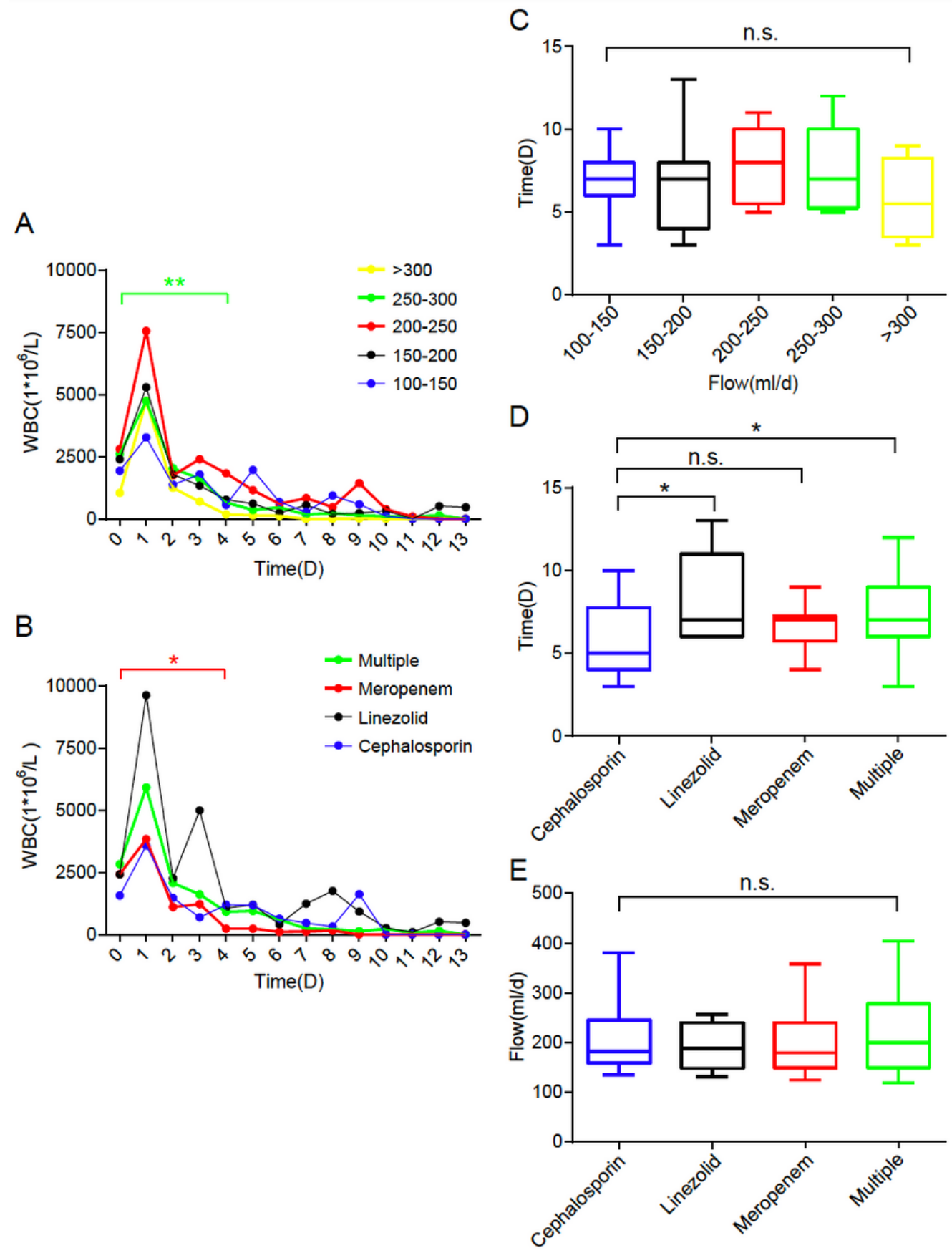

\section{Figure 4}

A. The WBC count change curves of different daily CSF drainage volumes; $B$. Comparison of the retention time of LCD among the different daily CSF drainage volumes; C. WBC change curves of different antibiotics; D. Comparison of the retention time of LCD among the different antibiotics; E. Comparison of daily CSF drainage flows of different antibiotics. n.s.: no statistical significance; *: $\mathrm{P}<0.05$. Data were represented as mean \pm s.e.m. 
A

.

C
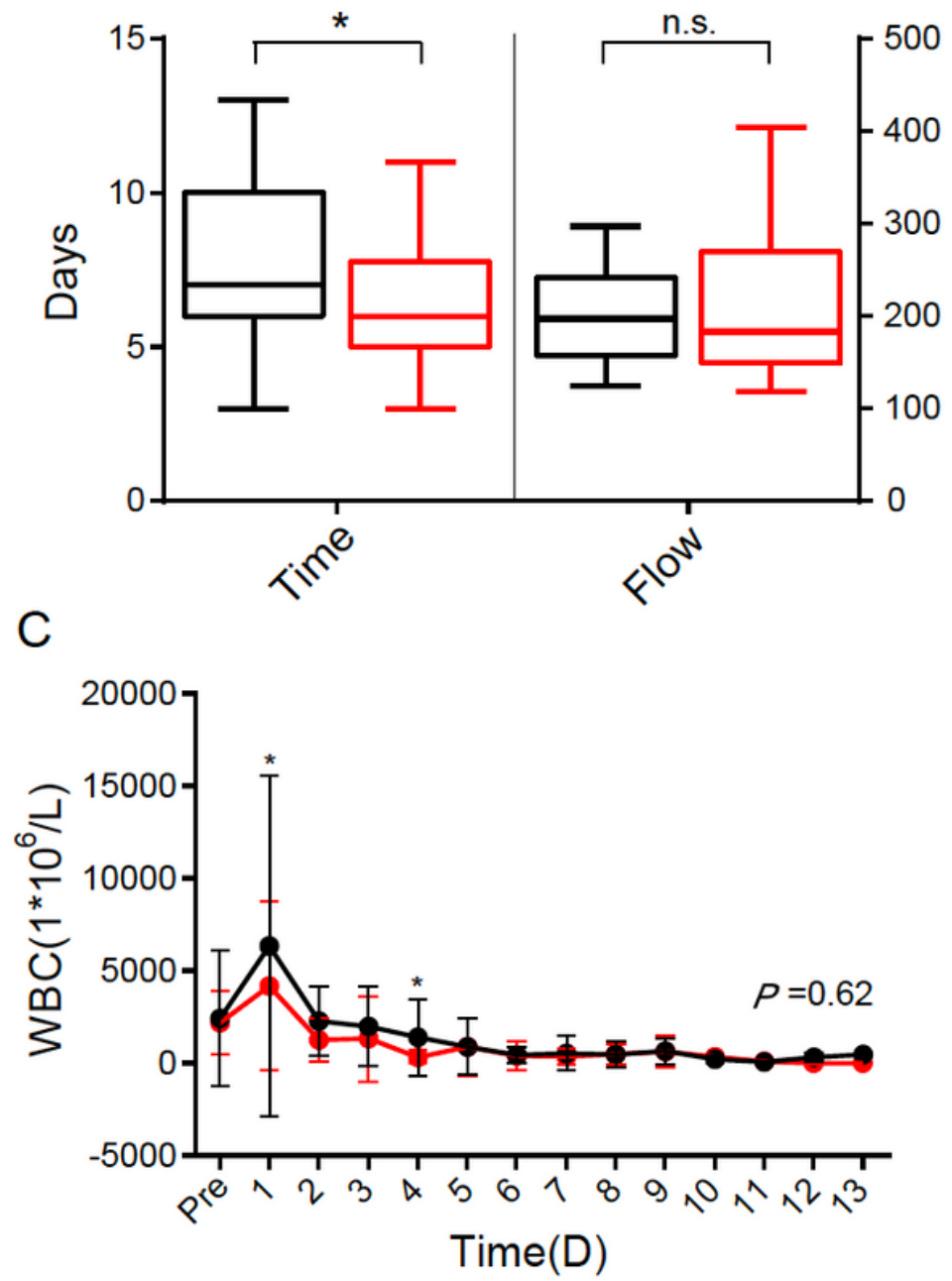

Supratentorial
B

Subtentorial
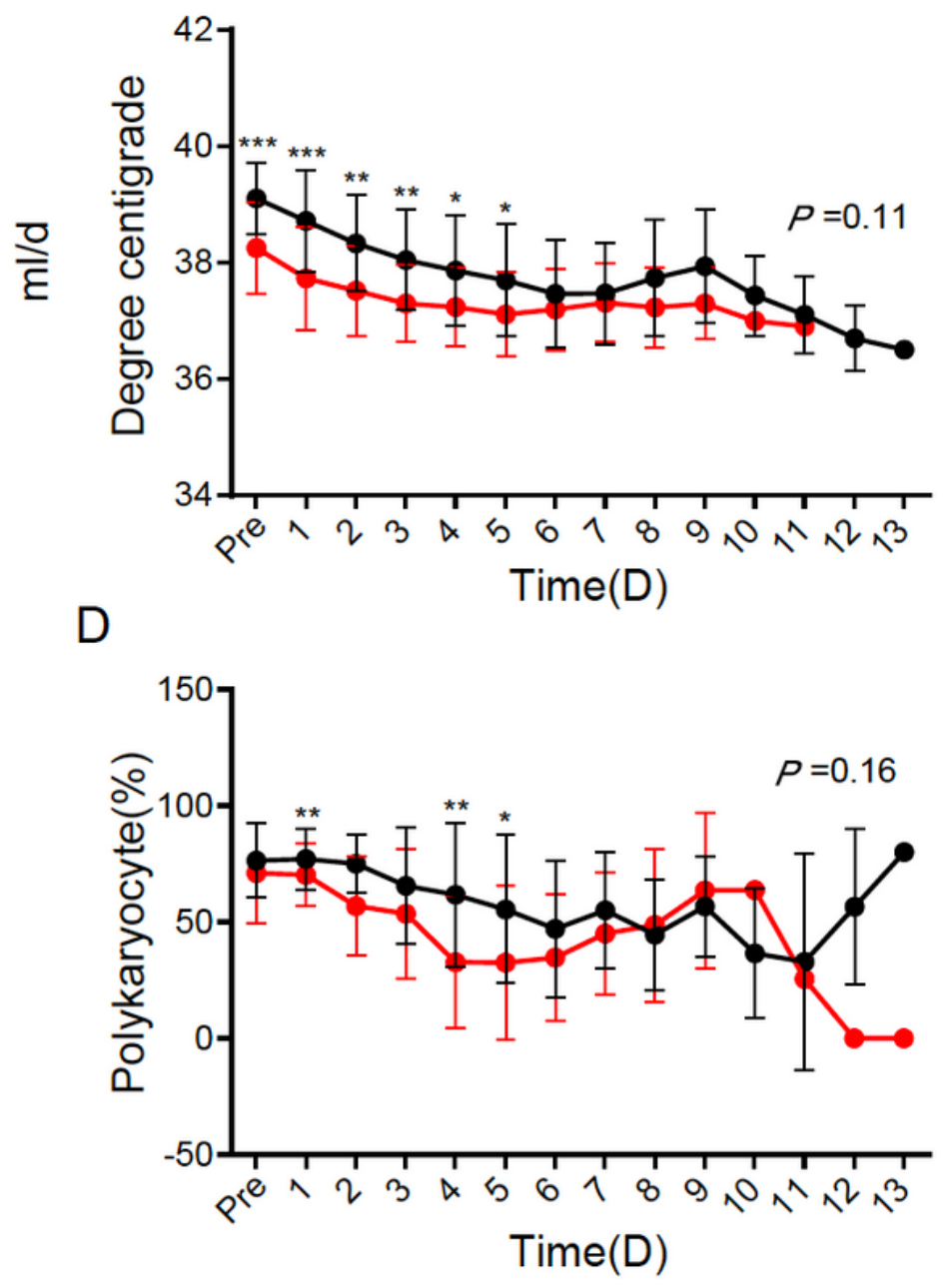

Figure 5

A. Comparison of the retention time and daily CSF drainage volume between supratentorial surgery and subtentorial surgery; B. Comparison of body temperature change curves between supratentorial surgery and subtentorial surgery; C. Comparison of WBC count change curves between supratentorial surgery and subtentorial surgery; D. Comparison of polykaryocyte percentage change curves between supratentorial surgery and subtentorial surgery. n.s.: no statistical significance; *: $P<0.05 ; * \star: P<0.01 ; * \star *$ : $P<0.001$. Data were represented as mean \pm s.e. $m$. 